Sex differences in contributions to care of young

\title{
Sex differences in
}

\section{responsiveness to begging in a cooperative mammal}

\author{
Sinead English ${ }^{1, *}$, Hansjoerg P. Kunc ${ }^{2}$, \\ Joah R. Madden ${ }^{1}$ and Tim H. Clutton-Brock ${ }^{1}$ \\ ${ }^{1}$ Department of Zoology, University of Cambridge, \\ Cambridge CB2 3EF, UK \\ ${ }^{2}$ Zoological Institute, University of Zurich, Zurich 8057, Switzerland \\ *Author for correspondence (se238@cam.ac.uk).
}

In species where young are provisioned by both parents, males commonly contribute less to parental care than females, and are less responsive to variation in begging rates. Similar differences in the care of young occur among adults in cooperative breeders, but fewer studies have investigated whether these are associated with differences in responsiveness. Here, we present results from a playback experiment investigating responsiveness to begging in the meerkat (Suricata suricatta), a cooperatively breeding mammal. Although increased begging rate raised the feeding rate of adults of both sexes, there was no consistent tendency for females to be more responsive than males. However, when we examined changes in the proportion of food items found that were fed to pups (generosity), we found that females were more responsive than males to increased begging rate. These results can be explained in terms of sex differences in dispersal: in meerkats, females are philopatric and receive considerable benefits from investing in young, both directly, by increasing group size, and indirectly, by recruiting helpers if they inherit the breeding position. In addition, they emphasize that generosity provides a more sensitive measure of responsiveness to begging than feeding rate, as it accounts for variation in foraging success.

Keywords: begging; parental care; feeding rate; signalling; meerkat

\section{INTRODUCTION}

In vertebrates, where both parents provision their young, females often contribute more to parental care than males (Clutton-Brock 1991). In addition, females are commonly more sensitive to signals of offspring need (Kolliker et al. 1998; Kilner 2002; Quillfeldt et al. 2004) such as begging rate, which has been shown to reflect hunger state in a number of species (Kilner \& Johnstone 1997). Sex differences in responsiveness to begging may arise because parents respond to different signals, vary in their response to the same signal or modify their behaviour differently according to their partner's response (Hinde 2006). These differences are likely to reflect sex differences in the costs and benefits of parental care (Lessells 2002), with the sex that accrues greater fitness benefits per unit of investment exhibiting higher sensitivity to offspring need.

have also been demonstrated in many cooperative breeders (reviewed in Cockburn 1998; Clutton-Brock et al. 2002). As in biparental systems, these differences may be a consequence of variation in the costs and benefits of care, and are likely to be associated with variation in responsiveness to offspring begging rate. While some studies have investigated how adults in a group vary in their responsiveness to begging according to breeding status or condition (Wright 1998; Bell 2008), only one study has demonstrated sex differences (MacGregor \& Cockburn 2002). To our knowledge, there is no evidence from cooperative breeders that the sex which invests more in the care of young also demonstrates greater responsiveness to increases in begging rate.

We investigated responsiveness to begging in a cooperatively breeding mammal, the meerkat (Suricata suricatta), which has a mobile begging system where begging calls are audible to all group members (Manser \& Avey 2000; Kunc et al. 2007). Meerkats are small (less than $1 \mathrm{~kg}$ ) carnivores living in groups of 3-50 individuals, with a dominant pair monopolizing reproduction and helpers of both sexes contributing to the care of young (Clutton-Brock et al. 2001). Pups start foraging with the group from approximately 30 days of age and receive prey items from helpers until they are nutritionally independent, at approximately three months old. There is high variation in pup feeding: females feed more than males and dominants contribute less than subordinates (Brotherton et al. 2001). Pups emit continuous begging calls to solicit feeding from adults, the rate of which indicates their hunger level (M. Manser 2002-2007, unpublished data).

We conducted a playback experiment to determine whether there were sex or status differences in responsiveness to increased signals of need from pups. We manipulated a single component of the begging signal (call rate) and measured the response of a focal individual. Most previous studies of the responses of adults to variation in juvenile begging rate have measured adult feeding rate, rather than the proportion of food found that is fed to offspring (generosity), which gives a measure of food allocation to young relative to that eaten by the adult. In this study, we examined the effects of begging rate on both the absolute feeding rate and generosity of dominant and subordinate adults of both sexes. We predicted that females would be more responsive than males and that dominants would be less responsive than subordinates, as suggested by natural variation in contributions to feeding young (Brotherton et al. 2001).

\section{MATERIAL AND METHODS}

This study was conducted between December 2005 and May 2006 on a population of wild meerkats in the Northern Cape, South Africa $\left(26^{\circ} 58^{\prime} \mathrm{S}, 21^{\circ} 49^{\prime} \mathrm{E}\right.$; see details in Clutton-Brock et al. 2001). All individuals in the population were identifiable by unique dye marks and habituated to ignore observers at close range (less than $1 \mathrm{~m}$ ).

We played $30 \mathrm{~min}$ low- and high-rate begging, in a random order, to focal individuals in 11 groups with pups at the peak feeding age (40-65 days). Playback stimuli were created from recordings of 11 female pups of similar ages from 11 different groups, using a different playback stimulus for each group. We manipulated the begging rate of stimuli by either adding or removing periods of background noise between calls to create the low (40 calls per min) and high (120 calls per min) treatments. These values lie within the natural range of 
Table 1. Effect of low and high call rates on (a) feeding rate and $(b)$ generosity. (Shown are the results of GLMMs including group and individual identities as random terms. Non-significant terms were deleted from the final models.)

\begin{tabular}{|c|c|c|c|c|}
\hline response term & explanatory terms & $F$ & $p$ value & effect (s.e.) \\
\hline \multirow[t]{6}{*}{ (a) feeding rate (g fed per hour) } & treatment & 7.82 & 0.008 & \multirow{6}{*}{$\begin{array}{l}\text { high: } 0.0(0.0) \text {, low: }-0.48(0.17) \\
\text { female: } 0.0(0.0) \text {, male: }-0.39(0.18)\end{array}$} \\
\hline & sex & 4.44 & 0.043 & \\
\hline & status & 0.36 & 0.551 & \\
\hline & treatment $\times$ sex & 0.95 & 0.334 & \\
\hline & treatment $\times$ status & 1.14 & 0.291 & \\
\hline & status $\times$ sex & 2.08 & 0.160 & \\
\hline \multirow[t]{6}{*}{ (b) generosity ( $\mathrm{g}$ fed/g found) } & treatment & 14.1 & $<0.001$ & \multirow{6}{*}{$\begin{array}{l}\text { high: } 0.0(0.0) \text {, low: }-0.41(0.11) \\
\text { female: } 0.0(0.0) \text {, male: }-0.31(0.11)\end{array}$} \\
\hline & sex & 8.06 & 0.008 & \\
\hline & status & 0.81 & 0.375 & \\
\hline & treatment $\times$ sex & 4.80 & 0.034 & \\
\hline & treatment $\times$ status & 0.23 & 0.631 & \\
\hline & status $\times$ sex & 2.39 & 0.133 & \\
\hline
\end{tabular}

begging rates (mean begging rate: $83.26 \pm 2.69$ calls per min, range: 23.35-137.15, from calculations based on 87 pups of 26 litters from 11 groups). In each group, the experiment was conducted on the dominant pair and a subordinate individual of each sex, over two consecutive days. The amplitude of the begging playback was kept to natural levels (Manser \& Avey 2000) and no more than two experiments were played consecutively to a group in one session, to avoid individuals habituating to calls and ceasing to respond. During the experiment, we followed the focal individual at a distance of $2 \mathrm{~m}$ with the speaker, recording the size of all prey items found, which was later used to estimate their biomass (as in Brotherton et al. 2001). Whenever the focal individual found a prey item, we noted whether it ate the item or took it to within $1 \mathrm{~m}$ of the loudspeaker and/or fed it to a pup (cf. Kunc et al. 2007). As pups in a group may respond to begging calls by guarding helpers more closely, we also recorded the presence of any pups within $2 \mathrm{~m}$ of the focal individual.

Statistical tests were performed using R (www.r-project.org). We used four general linear mixed models (GLMMs) to investigate the influence of begging rate, and its interaction with sex and dominance status, on adult feeding rate (biomass fed per hour), generosity (proportion of biomass found fed to pups) and foraging success (total biomass found). With the blocked design of our experiment (four focal individuals in each group), we could compare individuals within a group by fitting individual and group as random effects. Model simplification was conducted following Crawley (2002), with proportional data being arcsine transformed and feeding rate data being $\log$ transformed. Assumptions for normality and homogeneity of variances were fulfilled. All three-way interactions were nonsignificant and thus deleted from the final model.

\section{RESULTS}

Adult feeding rate was influenced both by playback treatment and sex, being higher in females (as in Clutton-Brock et al. 2001) and during the high begging rate playback, whereas it did not differ between dominants and subordinates (table $1 a$ ). In addition, there were no significant treatment $\times$ sex or treatment $\times$ status interactions (table $1 a$; figure $1 a$ ).

Similarly, the proportion of food items found that were fed to pups (generosity), increased during the high begging rate treatment, and was higher in females, while there was no difference between dominants and subordinates (table $1 b$ ). However, there was a significant treatment $\times$ sex interaction, indicating that females were more responsive to increased begging rate than males (table $1 b$; figure $1 b$ ).

Finally, dominants of both sexes had higher foraging success than subordinates $\left(F_{1,32}=4.87, p=0.027\right)$, although there were no significant differences in foraging success between the sexes $\left(F_{1,32}=0.93, p=\right.$ 0.33 ) or low- and high-rate playback treatments $\left(F_{1,43}=0.22, p=0.64\right)$.
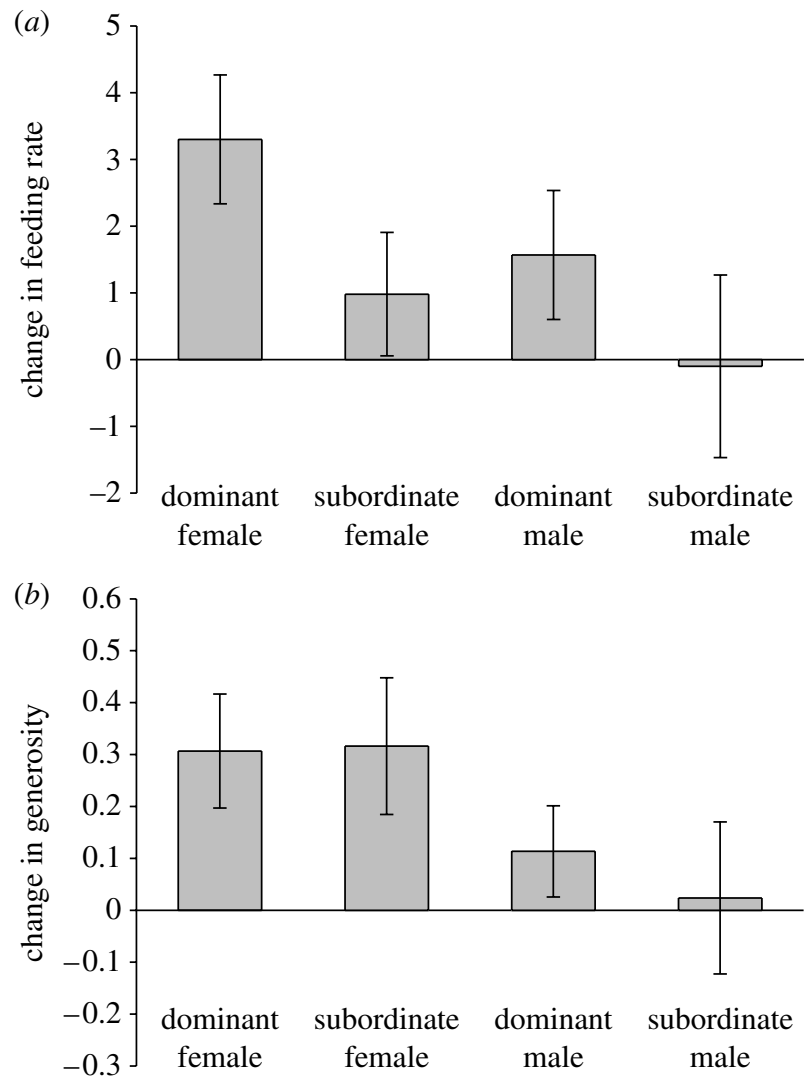

Figure 1. Change in (a) feeding rate and $(b)$ generosity from low- to high-rate begging treatments for different adults depending on their sex and dominance status. Each bar depicts mean ( \pm 1 s.e.) within-individual difference in response.

\section{DISCUSSION}

Increased begging rate raised both overall feeding rate and generosity, as predicted by theoretical and empirical studies (e.g. Godfray 1991; Burford et al. 1998; Glassey \& Forbes 2002). However, when we considered variation in the level of response, our results differed depending on the measure considered: we found sex differences in responsiveness to increased begging rate in terms of generosity but not feeding rate, while dominants and subordinates did not differ in responsiveness for either measure. Generosity is a more sensitive measure as it accounts 
for variation in foraging success. Even though foraging success did not differ between the sexes or across treatments, dominants were more successful at finding food than subordinates. Consequently, the contrast between subordinate females, who found less food but fed more of it to pups, and dominant males, who found more food but fed less of it to pups, is only evident when considering generosity. This demonstrates the importance of controlling for foraging success in studies of responsiveness to begging. Where direct observations of foraging behaviour are unfeasible, foraging success may be estimated through changes in body mass (e.g. Martins \& Wright 1993).

Both dominant and subordinate females were significantly more responsive to increased begging rate than males. Sex differences in responsiveness to increased begging rate are likely to be a true reflection of variation in sensitivity to offspring need, since begging rate indicates pup hunger level ( $M$. Manser 2002-2007, unpublished data). Our results differ from those of MacGregor \& Cockburn (2002) who found that male superb fairy wrens (Malurus cyaneus) were more responsive to the playback of begging, even though females contribute more to offspring care. They suggested that, as males spend less time at the nest, they have less information than females on offspring need and may consequently be more sensitive to increased vocal begging, whereas females may also respond to postural signals. Such information asymmetry is unlikely to explain differential responsiveness to begging in meerkats, since pups forage with the group and their begging calls can be heard throughout the group (Manser \& Avey 2000).

Sex differences in responsiveness to begging are probably a consequence of differences between males and females in the costs and benefits of investing in young. Sensitivity to the nutritional demands of pups is adaptive to adults as pups that receive more food have improved chances of survival (Clutton-Brock et al. 2001). Females, being the philopatric sex, have more to gain than males by maximizing pup survival, both through direct benefits of group augmentation and future benefits of recruiting helpers that may later assist them if they inherit the breeding position (Clutton-Brock et al. 2002). Sex differences in dispersal, therefore, could explain why females are both more generous to pups and more responsive to increases in begging rate.

As dominants contribute less to pup care than subordinates (Brotherton et al. 2001), we had expected them to be less responsive to begging. However, we found no difference between dominant and subordinate individuals of the same sex in responsiveness to increased begging rate, similar to Arabian babblers (Turdoides squamiceps), where both helpers and breeders increased their feeding rate in response to begging (Wright 1998). The lack of difference in responsiveness between dominants and subordinates here may be because dominants were more successful at foraging and consequently incurred fewer costs by increasing their generosity to hungrier offspring.

In conclusion, we found that females were more responsive to increased begging rate, in terms of generosity but not feeding rate. Females receive greater future pay-offs from investing in young than males, which may explain both why they invest more in young in general and respond more than males to changes in a pup's signal of need.

We thank Meerkat Project volunteers for their assistance with data collection, and M. Manser, A. Thornton, C. English, A. Cockburn and two anonymous reviewers for their comments. The Kotzes authorized us to work on their land and the Northern Cape Conservation Authority granted permission to conduct research. Funding was provided by NERC, BBSRC and the Swiss National Science Foundation (823A-53475).

Bell, M. B. V. 2008 Strategic adjustment of begging effort by banded mongoose pups. Proc. R. Soc. B 275, 1313-1319. (doi:10.1098/rspb.2008.0173)

Brotherton, P. N. M., Clutton-Brock, T. H., O'Riain, M. J., Gaynor, D., Sharpe, L., Kansky, R. \& McIlrath, G. M. 2001 Offspring food allocation by parents and helpers in a cooperative mammal. Behav. Ecol. 12, 590-599. (doi:10. 1093/beheco/12.5.590)

Burford, J. E., Friedrich, T. J. \& Yasukawa, K. 1998 Response to playback of nestling begging in the redwinged blackbird, Agelaius phoeniceus. Anim. Behav. 56, 555-561. (doi:10.1006/anbe.1998.0830)

Clutton-Brock, T. H. 1991 The evolution of parental care. Princeton, NJ: Princeton University Press.

Clutton-Brock, T. H., Brotherton, P. N. M., O'Riain, M. J., Griffin, A. S., Gaynor, D., Kansky, R., Sharpe, L. \& McIlrath, G. M. 2001 Contributions to cooperative rearing in meerkats. Anim. Behav. 61, 705-710. (doi:10. 1006/anbe.2000.1631)

Clutton-Brock, T. H., Russell, A. F., Sharpe, L. L., Young, A. J., Balmforth, Z. \& McIlrath, G. M. 2002 Evolution and development of sex differences in cooperative behavior in meerkats. Science 297, 253-256. (doi:10. 1126/science.1071412)

Cockburn, A. 1998 Evolution of helping behavior in cooperatively breeding birds. Annu. Rev. Ecol. Syst. 29, 141-177. (doi:10.1146/annurev.ecolsys.29.1.141)

Crawley, M. J. 2002 Statistical computing: an introduction to data analysis using $S$-plus. Chichester, UK: Wiley.

Glassey, B. \& Forbes, S. 2002 Muting individual nestlings reduces parental foraging for the brood. Anim. Behav. 63, 779-786. (doi:10.1006/anbe.2001.1973)

Godfray, H. C. J. 1991 Signalling of need by offspring to their parents. Nature 352, 328-330. (doi:10.1038/352328a0)

Hinde, C. A. 2006 Negotiation over offspring care?-a positive response to partner-provisioning rate in great tits. Behav. Ecol. 17, 6-12. (doi:10.1093/beheco/ari092)

Kilner, R. M. 2002 Sex differences in canary (Serinus canaria) provisioning rules. Behav. Ecol. Sociobiol. 52, 400-407. (doi:10.1007/s00265-002-0533-8)

Kilner, R. \& Johnstone, R. A. 1997 Begging the question: are offspring solicitation behaviours signals of need? Trends Ecol. Evol. 12, 11-15. (doi:10.1016/S0169-5347 (96)10061-6)

Kolliker, M., Richner, H., Werner, I. \& Heeb, P. 1998 Begging signals and biparental care: nestling choice between parental feeding locations. Anim. Behav. 55, 215-222. (doi:10.1006/anbe.1997.0571)

Kunc, H. P., Madden, J. R. \& Manser, M. B. 2007 Begging signals in a mobile feeding system: the evolution of different call types. Am. Nat. 170, 617-624. (doi:10.1086/ 521233) 
Lessells, C. M. 2002 Parentally biased favouritism: why should parents specialize in caring for different offspring? Phil. Trans. R. Soc. B 357, 381-403. (doi:10.1098/rstb. 2001.0928)

MacGregor, N. A. \& Cockburn, A. 2002 Sex differences in parental response to begging nestlings in superb fairywrens. Anim. Behav. 63, 923-932. (doi:10.1006/anbe. 2001.1991)

Manser, M. B. \& Avey, G. 2000 The effect of pup vocalisations on food allocation in a cooperative mammal, the meerkat (Suricata suricatta). Behav. Ecol. Sociobiol. 48, 429-437. (doi:10.1007/s002650000248)
Martins, T. L. H. \& Wright, J. 1993 Cost of reproduction and allocation of food between parent and young in the swift (Apus apus). Behav. Ecol. 4, 213-223. (doi:10.1093/ beheco/4.3.213)

Quillfeldt, P., Masello, J. F. \& Hamer, K. C. 2004 Sex differences in provisioning rules and honest signalling of need in Manx shearwaters, Puffinus puffinus. Anim. Behav. 68, 613-620. (doi:10.1016/j.anbehav.2003.12.002)

Wright, J. 1998 Helpers-at-the-nest have the same provisioning rule as parents: experimental evidence from playbacks of chick begging. Behav. Ecol. Sociobiol. 42, 423-429. (doi:10.1007/s002650050456) 